\title{
A Study on the Efficiency and Productivity of County-Level Hospitals from the Perspective of Regional Contrast in China: Data Envelopment Analysis and the Malmquist Index
}

\author{
Peng Li \\ First Affiliated Hospital of Anhui Medical University \\ Cunhui Wang \\ First Affiliated Hospital of Anhui Medical University \\ Nian-nian Li \\ First Affiliated Hospital of Anhui Medical University \\ Heng Wang ( $\sim$ hs1945010451@163.com ) \\ Anhui Medical University
}

\section{Research article}

Keywords: county-level hospital, data envelopment analysis, Malmquist Index, efficiency, China

Posted Date: May 22nd, 2020

DOI: https://doi.org/10.21203/rs.3.rs-18375/v1

License: (c) (1) This work is licensed under a Creative Commons Attribution 4.0 International License.

Read Full License 


\section{Title Page}

A Study on the Efficiency and Productivity of County-Level Hospitals from the Perspective of Regional Contrast in China: Data Envelopment Analysis and the Malmquist Index

\section{Authors and affiliations}

Peng $\mathrm{Li}^{1}$, Cunhui Wang ${ }^{1}$, Niannian $\mathrm{Li}^{1}$, Heng Wang ${ }^{1 *}$

${ }^{1}$ First Affiliated Hospital of Anhui Medical University, 218 Jixi Road, Hefei ,Anhui , 230022, PR, China

\section{* Corresponding author}

Professor Heng Wang

First Affiliated Hospital of Anhui Medical University,

218 Jixi Road, Hefei ,

Anhui , 230022, PR,

China

Tel./fax: +15855136806

E-mail: hs1945010451@163.com 


\begin{abstract}
Background. County-level public hospitals play an important role in China's medical tertiary health care network. Since a new round of medical reforms occurred in 2009, county-level public hospitals have conducted continuous exploration and reforms. To analyze the efficiency and productivity of 36 county-level public hospitals based three provinces in China.
\end{abstract}

Methods. We randomly selected 12 county-level hospitals from each 3 provinces based on economic levels and regional differences in China, finally, a total of 36 county-level hospitals were chosen, and a self-made questionnaire was used to investigate hospital operations for collecting data from 2011 to 2015. 2011-2015 is the twelfth five-year period of China's national economic and social development. Four input indicators and three output indicators were selected. Data envelopment analysis and the Malmquist index methods were used to measure the efficiency and productivity by the key indicators for each region.

Results. On average, four input indicators in three regions have continued to grow from 2011 to 2015 . The output in the three regions is directly proportional to the upward trend in inputs. On average, the three output indicators of hospitals in the eastern region are higher than the central and western regions. The technical efficiency of county-level public hospitals in the central, eastern, and western regions of China were on an upward trend, and the number of the technical efficiency, the pure technical efficiency, and the scale efficiency values reaching 1 in the three regions was more than half, respectively. The average of total factor productivity change for 2011-2015 in the central, eastern, and western regions was $1.016,0.997$, and 0.930 , respectively.

Conclusions. The efficiency of the central Chinese region was mainly affected by pure technical efficiency; however, scale efficiency changed to affect the efficiency of the eastern and western hospitals in 2015. The increase in production efficiency in the central region was driven by the technical efficiency. In the future hospital management, management innovation needs to be strengthened. The decline in productivity in the eastern region was due to the decline in the technical efficiency. At present, the eastern region pays attention to management innovation, but it is necessary to be alert to the 
adverse consequences of the expansion of hospital scale. The decline in productivity in the western region was due to the decline in the technological efficiency and technical efficiency. The hospitals should strengthen hospital management and blind scale expansion. Financial subsidies in the western region have a significant role in promoting the development of hospitals. The internal management innovation of hospitals in the eastern region has a positive effect on the technical efficiency of hospitals. The medical reform measures in the central region have positively promoted the efficiency of hospitals.

Keywords county-level hospital, data envelopment analysis, Malmquist Index, efficiency, China 


\section{Background}

China is a vast country with a large population. Medical services in China have always been an important livelihood issue for people-government relations. How nearly a billion rural residents can enjoy equal, fair, and highly accessible primary health care services has always been a focus of the government. As early as the 1950s, the formation of a rural tertiary health care network provided strong support for China's primary medical services ${ }^{[1]}$. County-level public hospitals, as the leaders of China's three-tiered rural health care network, have a positive effect on the normal use of tertiary health care networks ${ }^{[2-4]}$. As medical institutions for the treatment of frequently occurring and common diseases, county-level public hospitals have been affected by their own efficiency in addition to objective reasons such as regional economic and social development ${ }^{[4-5]}$. If a hospital's operating efficiency is low, more government investment will fail to improve its efficacy and waste resources, exacerbate the shortage of resources, and affect patients' medical experiences. If a hospital focuses only on the extensional development of human and material resources and other factors, it will ignore the core technologies of its competitiveness, which is the primary consideration for enhancing its efficiency. This is not conducive to the hospital's sustainable development ${ }^{[6]}$. The importance of studying county-level hospitals is obvious. This is not only a review of past efficiency analyses, but also a summary of the reason for the increase or decrease of past efficiency. This study describes how to scientifically and effectively evaluate the efficiency of a hospital, and the appropriate scientific analysis method is the key.

At present, the most common evaluation methods used worldwide to evaluate hospital efficiency are data envelopment analysis (DEA) and stochastic frontier analysis (SFA) ${ }^{[7-8]}$. Although SFA can separate the contribution of random effects and changes in technical efficiency, SFA cannot handle multiple outputs or consider random factors in medical care ${ }^{[9]}$. Thus, it is less practically used in health care efficiency research $^{[9-10]}$. Given that DEA can handle a variety of output and random factors in healthcare, we are more willing to use DEA for efficiency evaluation in the medical industry ${ }^{[9-10]}$.

We used the DEA method to evaluate hospital efficiency and the Malmquist Index for a cross-period efficiency analysis of hospital productivity. This study combined the DEA and Malmquist Index methods to analyze the operating efficiency of county-level 
public hospitals in the eastern, central, and western regions of China. Our application of DEA is based on the concept of technical efficiency and is directed at production technology at a distinct time. However, the production of decision-making units (DMUs) is generally a long-term and dynamic process ${ }^{[11]}$. Therefore, we must consider the impact of overall efficiency and technological efficiency on changes in productivity.

A review of the related literature found that China has a large number of research on the operating efficiency and productivity of hospitals as a whole, or on the research regarding allocation of resources to hospitals in the field of hospital efficiency and

productivity ${ }^{[18-20]}$. However, hospital efficiency has yet to be assessed according to geographical factors. This paper analyzes the efficiency and productivity of hospitals in different areas based on regional variations in China.

\section{Methods}

This paper studies the efficiency of a sample of Chinese hospitals based on the DEA method. DEA is a non-parametric research efficiency method based on the concept of relativity developed by Charnes, Cooper, and Rhodes ${ }^{[11]}$. It allows users to directly apply input and output data to create a non-parametric DEA model for analysis ${ }^{[15-16]}$. By judging whether the production DMUs is located on the "production frontier" that production may gather, the production frontier is an extension of the production function to the multi-output situation in economics, and it is a surface composed of Pareto optimal solutions with minimum input or maximum output ${ }^{[17]}$.

DMUs are the subject of research using the DEA method, and may be an enterprise, a hospital, or the equivalent representative. If a DMU is at the front line of production, it means that it is in a dominant position with the current level of technology and scale. When we use DEA to evaluate the efficiency of DMUs, we can get some relevant management information. With the information, we can not only analyze technical efficiency and scale efficiency but also the input redundancy, output shortage, and shadow analysis, which provide hospital managers and decision-makers evidence and support for the data. As part of management, reforms of research on management information are of great significance for clarifying the effectiveness and role of hospital reform.

Currently, frequently used models are Charnes, Cooper and Rhodes (CCR) models and Banker, Charnes and Cooper (BCC) models ${ }^{[11,18]}$. The CCR model was the first 
DEA model by Charnes, Cooper, and Rhodes in 1978. It is proposed that the hospital technical efficiency (TE) be measured in the case of constant returns to scale (CRS) . The BCC model was proposed by Banker, Charnes, and Cooper in 1984. In the case of variable returns to scale (VRS), pure technical efficiency (PTE) is calculated, and according to its laws, scale efficiency (SE) can be calculated, which is $S E=T E_{(C R S)} / P T E_{(V R S)}{ }_{[18-19]}$. Based on the data observed by each DMU, we determine whether the DMU is valid for DEA. It is essentially to determine whether the DMU is on the "production frontier" of the production set. That is to say, under certain technical conditions, we can get the maximum output set that each DMU input can form. The production frontier is the one in the economics where the production function is more productive $\mathrm{e}^{[8,20] \text {. }}$

In the CCR model, if the efficiency of DMU is 1 , the DMU is on the effective frontier of production and is at an ideal scale. However, if the DEA value is not 1 , the DMU is ineffective. In the BCC model, if the PTE is 1 , then it will means that the hospital has achieved the optimal output under the fixed input of resources such as existing human resources and financial resources; on the contrary, if it is not 1 , the resources invested will be excessive or insufficient, and it needs to improve based on actual conditions. If the SE is 1 , the hospital will be in the stage of constant scale returns, indicating that if the hospital increases resources $\mathrm{N}$ times, the output will increase by $\mathrm{N}$ times; if SE is not, the income scale will be increasing or decreasing. If the TE is 1 , it will means that the hospital is on the effective production frontier, and at the ideal scale, that is, in a "perfect" state ${ }^{[20]}$.

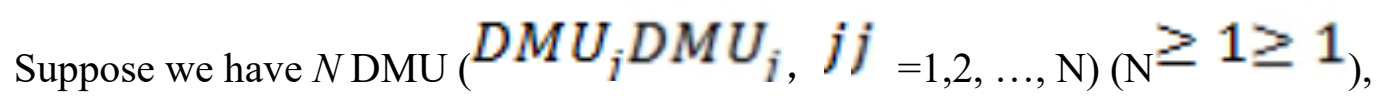
use $M$ inputs to produce $S$ outputs (M, S $\geq 1 \geq 1$ ). $\mathrm{X}_{0}, \mathrm{Y}_{0}$ represent $\mathrm{M}$ different inputs and S different output; $x_{i j} x_{i j}$ refers to the number of the $j j_{\text {th }}$ DMU to the $i i_{\text {th }}$ input, $x_{i j} x_{i j},\left({ }^{i i_{=1,2, \ldots, \mathrm{M}} ; j}=1,2, \ldots, \mathrm{N} ; x_{i j}>0\right)$ $\left.x_{i j}>0\right) ; \quad y_{r i} y_{r i}$ refers to the number of the $j j_{\text {th }}$ DMU to the $r r_{\text {th }}$

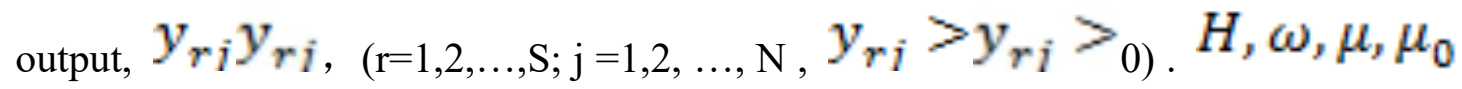


$H, \omega, \mu, \mu_{0}$ are the optimal value of the original planning problem, the input data, output data .and the solution of constant term, respectively. Its formula is expressed as $^{[21-22]}$ :

$$
\left(P_{C C R}^{I}\right)\left\{\begin{array}{l}
\max \mu^{T} Y_{0}=H \\
\omega^{T} x_{i j}-\mu^{T} y_{r j} \\
\omega^{T} x_{0}=1 \\
\omega \geq 0 \\
\mu \geq 0
\end{array} \quad \geq 0, j=1,2, \cdots, N\right.
$$

$$
\left(P_{C C R}^{I}\right)\left\{\begin{array}{l}
\max \mu^{T} Y_{0}=H \\
\omega^{T} x_{i j}-\mu^{T} y_{r j} \\
\omega^{T} x_{0}=1 \quad \geq 0, j=1,2, \cdots, N \\
\omega \geq 0 \\
\mu \geq 0
\end{array}\right.
$$

There are three types of returns to scale in the decision-making unit: which are constant, diminishing, and increasing. The constant of returns to scale means that the proportion of increase in the output indicator is equal to the increase in the input indicator. The diminishing of returns to scale means that the proportion increase in the output indicator is less than the increase in the input indicator. The increasing of returns to scale means that the proportion of increase in output indicators is greater than the increase in input indicators.

The DEA model has two orientations: 1) input-oriented and 2) output-oriented. The methodology used in this study is input-oriented. Because, in the area of health services, the input indicators are easier to control than the output indicators. When the output is constant, we can optimize use of resources by controlling the amount of input. ${ }^{[23-24]}$. 
The Malmquist Index (MI) was used by Caves et al. to introduce the Malmquist consumption curve into production analysis to calculate the productivity index by estimating the ratio between the distance functions ${ }^{[25-26]}$. It has been widely used since Färe (1994) used it to measure the distance function ${ }^{[27]}$. Productivity reflects the relationship between output indicators and input indicators. We used the Malmquist Index to analyze the productivity of hospitals over time. Through a cross-period analysis and comparison of five-year data panels, the dynamic changes in hospital efficiency in each region were observed. As with the DEA model selection, we still choose CRS and input-oriented when using the Malmquist index.

The Malmquist Index is used to calculate the productivity level of an organization that analyzes multiple input and multiple output indicators. Total factor productivity change (TFPC) represents the change of productivity levels during $t$ to $t+1$ period. Caves et al.(1982) further decomposed the index into technological change (TC) and technical efficiency change (TEC) ${ }^{[26]}$. Färe (1994) further decomposed efficiency change into pure technical efficiency change (PTEC) and scale efficiency changes ${ }_{(\mathrm{SEC})^{[27]} .} T F P C=T E C^{*} E C$ and $T E C=P T E C^{*} S E C$. ${ }^{*}<1$ indicates productivity decline, $\mathrm{MI}=1$ indicates productivity unchanged, and $\mathrm{MI}>1$ indicates growth. All MI averages are geometric means. Its formula is expressed as:

$$
\begin{aligned}
& M_{i}^{t}=\frac{D_{i}^{t}\left(x^{t+1}, y^{t+1}\right)}{D_{i}^{t}\left(x^{t}, y^{t}\right)} \\
& M_{i}^{t+1}=\frac{D_{i}^{t+1}\left(x^{t+1}, y^{t+1}\right)}{D_{i}^{t+1}\left(x^{t}, y^{t}\right)}
\end{aligned}
$$

$$
M_{i}^{t}\left(x^{t+1}, y^{t+1}, x^{t}, y^{t}\right)=\sqrt{\frac{D_{i}^{t}\left(x^{t+1}, y^{t+1}\right)}{D_{i}^{t}\left(x^{t}, y^{t}\right)} \cdot \frac{D_{i}^{t+1}\left(x^{t+1}, y^{t+1}\right)}{D_{i}^{t+1}\left(x^{t}, y^{t}\right)}}
$$

$$
\begin{aligned}
M_{i}^{t+1}\left(x^{t+1}, y^{t+1}, x^{t}, y^{t}\right) & \\
& =\frac{D_{i}^{t+1}\left(x^{t+1}, y^{t+1}\right)}{D_{i}^{t}\left(x^{t}, y^{t}\right)} \cdot \sqrt{\frac{D_{i}^{t}\left(x^{t+1}, y^{t+1}\right)}{D_{i}^{t+1}\left(x^{t+1}, y^{t+1}\right)} \cdot \frac{D_{i}^{t}\left(x^{t}, y^{t}\right)}{D_{i}^{t+1}\left(x^{t}, y^{t}\right)}}
\end{aligned}
$$


Where $M_{i}^{t+1} M_{i}^{t+1}$ is the Malmquist productive index $;^{t+1} x^{t+1}$ is the DMU's output of period $t+1 ; y^{t+1} y^{t+1}$ is the DMU's input of period $t+1 ; x^{t} x^{t}$ is the DMU's output of period $t ; y^{t} y^{t}$ is the DMU's input of period $t$; $D_{i}^{t}\left(x^{t}, y^{t}\right) D_{i}^{t}\left(x^{t}, y^{t}\right)$ is a vector of distance function estimate for the $\mathrm{n}$ DMUs in period 1 relative to estimated technology in period 1; $D_{i}^{t+1}\left(x^{t+1}, y^{t+1}\right) D_{i}^{t+1}\left(x^{t+1}, y^{t+1}\right)$ is a vector of distance function estimate for the $\mathrm{n}$ DMUs in period 2 relative to estimated technology in period 2; $D_{i}^{t}\left(x^{t+1}, y^{t+1}\right) D_{i}^{t}\left(x^{t+1}, y^{t+1}\right)$ is a vector of distance function estimate for the $\mathrm{n}$ DMUs in period 2 relative to estimated technology in period 1; $D_{i}^{t+1}\left(x^{t}, y^{t}\right) D_{i}^{t+1}\left(x^{t}, y^{t}\right)$ is a vector of distance function estimate for the $\mathrm{n}$ DMUs in period 1 relative to estimated technology in period $2^{[28]}$.

\section{Research design}

\subsection{Samples and sources of data}

In early 2015, Jiangsu, Fujian, Anhui, and Qinghai Provinces in China were identified as China's comprehensive pilot programs for a deepening medical reform. According to regional differences, we have selected one province from eastern, central and western China, respectively, which were Fujian, Anhui and Qinghai Province. When selecting county-level hospitals in each province, the following two factors were considered: Firstly, regional and economic factors, four hospitals in the eastern, central, and western regions of each province were selected, and finally, 12 hospitals from each province were selected. Secondly, the willingness of investigating hospitals to participate in our study were considered. Each of the 12 county-level public hospitals was sampled according to the level of economic development. Anhui's 12 hospitals are numbered A1-A12 (central), Fujian's hospitals are B1-B12 (eastern), and Qinghai's hospitals are C1-C12 (western).

The choice of the year of the data is mainly based on the consideration that 20112015 is the twelfth five-year period of China's national economic and social development. It has specific plans for all aspects of the country and builds a grand 
blueprint for social development. This time period is chosen to be comparable to the relevant policy implementation results ${ }^{[29]}$.

\subsection{Input and output indicators}

Firstly, after reviewing and analyzing studies of DEA in China work by Ozcan $(2008)^{[30]}$, O’Neil(2008) $)^{[8]}$, Hollingsworth(2003) ${ }^{[16]}$, ten input indicators and nine output indicators were counted by using the word frequency analysis method ${ }^{[31-32]}$. Thus, four input indicators and three output indicators were selected. The four input indicators are: 1) the actual number of physicians, 2) the actual number of nurses, 3) the total expenditures, and 4) the fixed assets. The three output indicators are: 1) the number of outpatient and emergency visits, 2) the medical income, and 3) the actual occupancy of the total bed days.

\subsection{Statistical analysis}

Microsoft Excel 2007 software was used for data entry. 12 sample hospitals in each of the three regions were used as DMUs to perform a static analysis based on CCR model and BCC model calculation efficiency by using DEAP 2.1 software. The productivity analysis was based on the Malmquist Index.

\section{Results}

\subsection{Description of the three regions' input and output indicators}

Regarding inputs, Table 1 shows that, on average, four input indicators in three regions have continued to grow from 2011 to 2015 . From 2011 to 2015, the hospitals in the eastern region invested more than central and western regions, with the least in the western. Regarding output, Table 2 shows that the output in the three regions is directly proportional to the upward trend in inputs. On average, the three output indicators of hospitals in the eastern region are higher than the central and western regions, with the least in the western.

\subsection{Distribution of the number of TE, PTE and SE values reaching 1 of county- level public hospital}

In Table 3, the numbers for TE, PTE, and SE represent the number of hospitals with TE, PTE, and SE values reaching 1 for this year, and the numbers in brackets represent the percentage. The number of TE, PTE, and SE values reaching 1 in the three regions' 
was more than $6(\geq 50 \%)$, the highest number of hospitals with efficient TE was 10 , in the eastern and western regions in 2013, respectively. A minimum number of 7 hospitals in the eastern and western regions were technically efficient in 2011. See Table 3.

\subsection{Returns to Scale of County-Level Public Hospitals in the Studied Regions}

The proportion of hospitals with increasing returns to scale in the studied regions was relatively high, and the decreasing proportion of the central hospitals was the lowest. From 2013 to 2015, the number of hospitals with increasing returns to scale in hospitals in the central region gradually increased. From 2011 to 2015, the number of hospitals with increasing returns to scale in the eastern and western regions all transitioned from increasing to decreasing. Taking 2011 as an example, the returns to scale of four hospitals in the central region are constant, no hospitals is diminishing, and eight hospitals are increasing; the return to scale of two hospitals in the eastern region are constant, three hospitals are diminishing, and seven hospitals are increasing; the returns to scale of two hospitals in the western region are constant, three hospitals are diminishing, and seven hospitals are increasing. The number of hospitals with increasing returns in scale has exceeded 50\% in three regions in 2011-2015, which is due to the fact that hospitals have been expanding in recent years. See Figure 1.

\subsection{County-Level Public Hospital Efficiency Means in the Regions}

The TE of the central and eastern regions was on an upward trend, and the growth patterns of the three regions varied from 2011-2015 (see Figure 2). The TE of the central region decreased first (2011-2013), then increased (2013-2015). The TE of eastern region first increased rapidly (2011-2013). After a slow decline (2013-2014) and ramptype growth (2014-2015), the trend in the western region was obvious, with a rapid rise (2011-2012) followed by a rapid decline (2012-2013) followed by a slow rise (20132014) and a rapid increase (2014-2015) of the hospitals. From 2012 to 2014, the TE of the eastern region was higher than that of the central and eastern regions. From 2011 to 2014, the PTE of the eastern region was higher than that of the central and western regions. See Figures 3.

\subsection{Analysis of the results based on the DEA-Malmquist Index model}

From the overall average TFPC, the average TFPC from 2011-2015 for the five years 
in the central region was 1.016 , which was a $1.6 \%$ increase. The average TFPC for the eastern and western regions from 2011-2015 was 0.997 and 0.930 , down $0.3 \%$ and $7.0 \%$, respectively. The change trend of TFPC in the central region was consistent with the overall change in TEC and TC (Figure 4). TEC was consistent with SE (Figure 4). The changes in TFPC and TC in the eastern region were consistent (Figure 5). TEC was consistent with changes in scale efficiency (Figure 5). The extent of TFPC and TEC in the western region remained highly consistent (Figure 6). TEC and SEC were consistent, but the former was much lower than the latter (Figure 6).

TFPC in the central, eastern, and western regions of China increased from 2011 to 2012, rising by $1.2 \%, 7.9 \%$, and $17.1 \%$, respectively. (See Table 4 and Figures 4-6). TEC in the three regions increased to varying degrees. The western region rose rapidly, followed by the east, and the central region was the lowest. In addition to the increase in $\mathrm{TC}$ in the western region, TEC also increased by $0.8 \%$, which is why the western region had the highest TFPC in 2011-2012. In 2012-2013, the productivity in the western region declined, and was lower than the average TFPC in the western region. In 2013-2014, productivity in the western region improved, but productivity in the central and western regions declined. In 2014-2015, TFPC in the central region increased by $5.90 \%$, and TFPC in the eastern region remained at a declining level, decreasing by $9.30 \%$. TFPC in the western region was lower than the average TFPC.

\section{Discussion}

More than half of the hospitals' TE in each region showed effective status, and the efficiency level indicated an increasing trend. However, TFP in the eastern and western regions declined from 2011 to 2015.

The proportion of DEA effective units in the TE, PTE, and SE of the three regions' hospitals reached more than 50\%, and the highest was 91.67\%. From 2011 to 2015 units, the average TE in the three regions showed an increasing trend. Similar studies recode resembling degrees of hospital efficiency, for example, in Nepal ${ }^{[33]}$, in $\mathrm{Japan}^{[34]}$, in the Angola $^{[35]}$, in Vietnam ${ }^{[36]}$. The average growth rate was the fastest in the western Chinese region, followed by the eastern Chinese region, and the central Chinese region was in the last, but the average growth rate was less than $1.5 \%$. The efficiency values Chinese of the hospitals in the three regions increased by varying degrees from 2014 to 2015. This is because the PTE in the central and western regions increased and the SE 
values were at relatively high levels. The SE in the eastern region increased, and PTE remained high. Since the 2012 reform of county-level public hospitals, they have implemented a series of measures for their existing management systems, compensation mechanisms, personnel distribution, and cost structures ${ }^{[5]}$. Although the TE of the hospitals in the three Chinese regions declined, overall it was trending upward. In addition, from the Malmquist Index analysis of the three Chinese regions, the average TFPC in the central region increased by $1.6 \%$ between 2011 and 2015, and the average TFPC in the eastern and western Chinese regions decreased by $0.3 \%$ and $7.0 \%$, respectively. Although TEC increased in the central and eastern Chinese regions, the level of TC in the central region was significantly higher than in the eastern Chinese region. As a result, productivity in the central region rose while productivity in the eastern region declined. The average TFPC decline in the western region was due to the decline of TE.

The efficiency of the central Chinese region was mainly affected by PTE; however, SE changed to affect the efficiency of the eastern and western hospitals in 2015.

The DEA analysis indicated that changes in hospital efficiency at different times were affected differently by PTE and SE. From 2011 to 2015, TE in the central Chinese region was mainly affected by PTE ${ }^{[37]}$. From 2011 to 2014, TE in the eastern and western Chinese regions was mainly affected by PTE. In 2015, TE was more affected by SE. In the central Chinese region, the improvement in the hospitals' efficiency depended on management, innovation, and use of new technologies. The situation in the eastern and western hospitals changed in 2015 and was no longer PTE but an impact by SE. Since the 2012 Chinese hospital reforms, the provinces have invested considerable human resources, financial resources, and material resources for improvements. However, due to serious contradictions between the hospitals' management systems and price mechanisms, reforms have just begun. When reforms were implemented, most hospitals reformed around the mechanism of "drugmaintaining medicine" as the key link to ease the current "difficult" conflict. With the improvement in hospital management and the ability to integrate and utilize resources, the scale of the eastern and western Chinese hospitals gradually became more prominent than the previous management and other technical issues. Although the proportion of returns to the scale of the Chinese hospitals in the eastern and western regions gradually increased, the government clearly noted that according to the functional positioning of county-level public hospitals, their construction and large- 
scale equipment configuration should be strictly controlled. Therefore, Chinese hospitals in the eastern and western regions should pay attention to adjusting their overall scale in future development. We must make scientific overall framework in the areas of hospital basic construction and the purchase of large-scale medical equipment to avoid the increase in hospital operating costs caused by blind expansion, and we must also ensure that the scale is conducive to normal medical activities.

\section{TC affected TFPC in the central and western Chinese regions, and TEC affected the efficiency of hospitals in the eastern region.}

An analysis of the Malmquist Index revealed that the productivity improvement in the central Chinese region mainly benefited from the progress in TC, while the decrease was also due to limited technological progress. Although it declined in 2013-2014, it has since recovered. The elimination of measures such as "drug-maintaining medicine" had a certain influence on the operation of the hospitals in the initial stage of implementation, and TFPC decreased. However, after the implementation, the hospitals adjusted the costs of medical services and the government provided certain financial compensation. More attention was paid to the innovation and progress of medical technology and the hiring and training of personnel, and the hospitals' TC rapidly improved. The efficiency of production in the eastern region shifted from an original rise to a decline. The change in productivity was mainly due to the decline in TEC. TEC in the eastern region has generally shown a gradual upward trend, while TC has maintained a downward trend. Since the reform of the public hospitals at the county level in the eastern region, attention has been paid to management innovation.

Although progress has been slow, many new explorations have been conducted in the management system, such as medical reforms. The leadership team is served by the party and the local government. Party committees and government departments assume responsibility for the construction, supervision, and management of Chinese hospitals. However, Chinese hospitals remain responsible for the management of personnel and operations. TFPC in the western region mainly depends on TC. The economy in the western provinces is weaker than in the central and eastern regions. China has provided financial support for many years, and TFPC increased in 2013-2014. However, Chinese the actual medical capacity of the Chinese hospitals has not improved. The overall internal management and resource integration in the hospitals has improved to a certain degree due to economic and geographical factors. However, the lack of application of

new technologies and innovations and the hiring of personnel have directly led to the 
underdevelopment of technological efficiency and have reduced the hospitals' TFPC.

Currently, Tianchang in the central region, Youxi in the eastern region, and Huzhu in the western region are the county-level model hospitals for comprehensive reform ${ }^{[38]}$. Some practices have improved their TE, PTE, and SE. However, their experience cannot be easily reproduced. Only under by understanding the insufficiency of the hospital itself, the solution can be based on the actual situation in order to fundamentally solve the problem. In view of the current status of the eastern, central, and western regions, while maintaining the current high efficiency, it is necessary to put the cognition of the hospital's own short boards. While summing up the progress in TC, the central and eastern Chinese hospitals should note their own shortcomings in TC. The improvement of a hospitals' TC mainly benefits from the improvement of its management level and the optimization of its management models. Good management models and mechanisms can stimulate the enthusiasm of medical staff and rationally use limited medical resources to improve the efficiency of the use of medical resources. The TE of the central Chinese region was mainly caused by insufficient SE, and it is necessary to focus on the impact of SE. In the eastern region, both PTE and SE are declining, suggesting that hospitals should pay attention to improving resource utilization during the process of independent operation. Hospitals should focus on the impact of scale expansion.

Hospitals in the western region should assess the improvement in technical efficiency and avoid the lack of technical impetus for their development because of their weak technical power, and should also pay attention to the introduction of technology and knowledge reserves. Chinese hospitals need to focus on hiring qualified personnel and long-term training and pay attention to the application of new medical equipment. Hospitals also must continuously innovate in diagnosis and treatment technology, reasonably regulate and optimize the existing treatment procedures, and pay attention to the improvement of routine treatment measures to promote the technical progress of medical services.

\section{Conclusion}

The efficiency of the central Chinese region was mainly affected by pure technical efficiency; however, scale efficiency changed to affect the efficiency of the eastern and western hospitals in 2015. The increase in production efficiency in the central region 
was driven by the technical efficiency. In the future hospital management, management innovation needs to be strengthened. The decline in productivity in the eastern region was due to the decline in the technical efficiency. At present, the eastern region pays attention to management innovation, but it is necessary to be alert to the adverse consequences of the expansion of hospital scale. The decline in productivity in the western region was due to the decline in the technological efficiency and technical efficiency. The hospitals should strengthen hospital management and blind scale expansion. Financial subsidies in the western region have a significant role in promoting the development of hospitals. The internal management innovation of hospitals in the eastern region has a positive effect on the technical efficiency of hospitals. The medical reform measures in the central region have positively promoted the efficiency of hospitals.

\section{List Abbreviations}

DEA: Data Envelopment Analysis; DMUs: Decision-Making Units; TE: Technical

Efficiency PTE: Pure Technical Efficiency; SE: Scale Efficiency; TFPC: Total Factor Productivity Change; TC: Technological Change; TEC: Technical Efficiency Change; PETC: Pure Technical Efficiency change; SEC: Scale Efficiency Changes

\section{Declarations}

Ethics approval and consent to participate

Not applicable.

\section{Consent to publish}

Not applicable.

\section{Availability of data and materials}

The datasets used and/or analysed during the current study are available from the corresponding author on reasonable request.

\section{Competing interests}


The authors declares that they no competing interests.

\section{Funding}

This research was supported by the National Natural Science Foundation of China (No.71774001 and No. 71473003). The organization has no role in the designing of the study, data collection, analysis, and interpretation of data and in writing the manuscript.

\section{Authors' contributions}

PL and CHW designed the study, collected the data, analysed the data and and drafted the manuscript. NNL analysised the data, and drafted the background of the manuscript. HW supervised the study, and contributed to all section of the paper. All authors critically reviewed, edited and approved the final manuscript.

\section{Acknowledgements}

This research was supported by grants from the National Science Foundation of China (No.71473003). We would like to thank the hospital and the hospital staff for their support and help. We appreciate the contribution of Yunwu Zhao and Hongyan Yin to the data collection of this article.

\section{Reference:}

1. Huang Y, Z. L., Li Y, Zhou X, Liu P, Zhong D, Performance evaluation on healthcare reform policy in rural China: a systematic review. Chinese Journal Evidence Based Medicine 2012, 12, 293-304.

2. Li, X.; Lu, J.; Hu, S.; Cheng, K. K.; De Maeseneer, J.; Meng, Q.; Mossialos, E.; Xu, D. R.; Yip, W.; Zhang, H.; Krumholz, H. M.; Jiang, L.; Hu, S., The primary health-care system in China. Lancet 2017, 390, (10112), 2584-2594.

3. Gai, R. Y.; Zhou, C. C.; Xu, L. Z.; Zhu, M.; Wang, X. Z.; Li, S. X.; Zheng, W. G.; Song, P. P.; Yang, X. L.; Fang, L. Y.; Zhen, Y. C.; Tang, W., Health resource allocation and productive efficiency of Chinese county hospitals: data from 
1993 to 2005. Bioscience trends 2010, 4, (5), 218-24.

4. Xu, S.; Bian, C.; Wang, H.; Li, N.; Wu, J.; Li, P.; Lu, H., Evaluation of the implementation outcomes of the Essential Medicines System in Anhui countylevel public hospitals: a before-and-after study. BMC health services research 2015, 15, 403 .

5. Lee, K. H.; Park, J.; Lim, S.; Park, S. C., Has competition increased hospital technical efficiency? The health care manager 2015, 34, (2), 106-12.

6. Chen, A.; Kim, E. A.; Aigner, D. J.; Afifi, A.; Caprioli, J., Index to Estimate the Efficiency of an Ophthalmic Practice. JAMA ophthalmology 2015, 133, (8), 924-9.

7. O'Neil, L. L.; Wiest, O., Structures and energetics of base flipping of the thymine dimer depend on DNA sequence. The journal of physical chemistry. $B$ 2008, 112, (13), 4113-22.

8. Kontodimopoulos, N.; Papathanasiou, N. D.; Flokou, A.; Tountas, Y.; Niakas, D., The impact of non-discretionary factors on DEA and SFA technical efficiency differences. Journal of medical systems 2011, 35, (5), 981-9.

9. Worthington, A. C., Frontier efficiency measurement in health care: a review of empirical techniques and selected applications. Medical care research and review : MCRR 2004, 61, (2), 135-70.

10. Paganini, J. M., [Quality and efficiency in hospitals]. Boletin de la Oficina Sanitaria Panamericana. Pan American Sanitary Bureau 1993, 115, (6), 482510.

11. Zhang, X.; Zhao, L.; Cui, Z.; Wang, Y., Study on Equity and Efficiency of Health Resources and Services Based on Key Indicators in China. PloS one 2015, 10, (12), e0144809.

12. Li NN, W. C., Ni H, Wang H, Efficiency and Productivity of county-level public hospitals based on the data envelopment analysis model and malmquist index in Anhui, Chin. Chinese medical journal 2017, 130(23), 2836-43.

13. Sun, J.; Luo, H., Evaluation on equality and efficiency of health resources allocation and health services utilization in China. International journal for 
equity in health 2017, 16, (1), 127.

14. Grannemann, T. W.; Brown, R. S.; Pauly, M. V., Estimating hospital costs. A multiple-output analysis. Journal of health economics 1986, 5, (2), 107-27.

15. Hollingsworth, B., Non-parametric and parametric applications measuring efficiency in health care. Health care management science 2003, 6, (4), 203-18.

16. Hofmarcher, M. M.; Paterson, I.; Riedel, M., Measuring hospital efficiency in Austria--a DEA approach. Health care management science 2002, 5, (1), 7-14.

17. Aparicio, J.; Barbero, J.; Kapelko, M.; Pastor, J. T.; Zofio, J. L., Testing the consistency and feasibility of the standard Malmquist-Luenberger index: Environmental productivity in world air emissions. Journal of environmental management 2017, 196, 148-160.

18. Hollingsworth, B.; Parkin, D., The efficiency of the delivery of neonatal care in the UK. Journal of public health medicine 2001, 23, (1), 47-50.

19. Wei QL, C. W., The production frontier of DEA and its applications in microeconomics, proceedings of the Second International Conference on Systems Science and Systems Engineering. International Academic Publishems 1993, 107-12.

\section{Figure Legends:}

Figure 1 Returns to scale of public hospitals at the county level from 2011-2015 in the various Chinese regions

Figure 2 Average TE of public hospitals at the county level in the different regions from 2011-2015

Figure 3 Average PTE and SE of public hospitals at the county level in the different Chinese regions from 2011-2015

Figure 4 TEC, TC, PTEC, SEC and TFPC in the central Chinese region from 20112015

Figure 5 TEC, TC, PTEC, SEC and TFPC in the eastern Chinese region from 20112015

Figure 6 TEC, TC PTEC, SEC and TFPC in the western Chinese region from 2011- 
Table 1 Description of input indicators by regions from 2011 to 2015

\begin{tabular}{|c|c|c|c|c|c|c|c|c|}
\hline & \multicolumn{2}{|c|}{$\begin{array}{l}\text { The actual } \\
\text { number of } \\
\text { physicians }\end{array}$} & \multicolumn{2}{|c|}{$\begin{array}{l}\text { The actual } \\
\text { number of } \\
\text { nurses }\end{array}$} & \multicolumn{2}{|c|}{$\begin{array}{l}\text { The total } \\
\text { expenditures }\end{array}$} & \multicolumn{2}{|c|}{ The fixed assets } \\
\hline & Mean & $\begin{array}{l}\text { Std. } \\
\text { D }\end{array}$ & Mean & $\begin{array}{c}\text { Std. } \\
\text { D }\end{array}$ & Mean & Std.D & Mean & Std.D \\
\hline \multicolumn{9}{|l|}{ Central } \\
\hline 2011 & 151.42 & 51.49 & $\begin{array}{c}227.0 \\
0\end{array}$ & 54.95 & $1.09 \times 10^{4}$ & 4086.71 & 6596.62 & 2986.52 \\
\hline 2012 & 159.67 & 53.32 & $\begin{array}{c}243.3 \\
3\end{array}$ & 52.43 & $1.34 \times 10^{4}$ & 5355.80 & 7506.91 & 3845.51 \\
\hline 2013 & 179.25 & 59.28 & $\begin{array}{c}266.4 \\
2\end{array}$ & 75.42 & $1.55 \times 10^{4}$ & 6735.38 & $1.04 \times 10^{4}$ & 5810.12 \\
\hline 2014 & 187.58 & 59.86 & $\begin{array}{c}281.0 \\
8\end{array}$ & 77.43 & $1.81 \times 10^{4}$ & 7829.73 & $1.15 \times 10^{4}$ & 7351.70 \\
\hline 2015 & 195.00 & 63.04 & $\begin{array}{c}300.2 \\
5\end{array}$ & 95.55 & $2.08 \times 10^{4}$ & 9406.54 & $1.32 \times 10^{4}$ & 9807.61 \\
\hline
\end{tabular}

Eastern

\begin{tabular}{|c|c|c|c|c|c|c|c|c|}
\hline 2011 & 174.58 & 82.59 & $\begin{array}{c}260.0 \\
0\end{array}$ & 81.59 & $1.48 \times 10^{4}$ & 8253.69 & $1.00 \times 10^{4}$ & 5235.61 \\
\hline 2012 & 182.00 & 85.02 & $\begin{array}{c}280.3 \\
3\end{array}$ & 78.45 & $1.73 \times 10^{4}$ & 8474.46 & 9254.34 & 4161.44 \\
\hline 2013 & 189.25 & 95.36 & $\begin{array}{c}289.3 \\
3\end{array}$ & 75.30 & $1.95 \times 10^{4}$ & 9107.82 & 9155.04 & 3692.54 \\
\hline 2014 & 199.58 & 99.37 & $\begin{array}{c}319.5 \\
0\end{array}$ & 80.05 & $2.22 \times 10^{4}$ & 9607.70 & $1.03 \times 10^{4}$ & 4228.82 \\
\hline
\end{tabular}




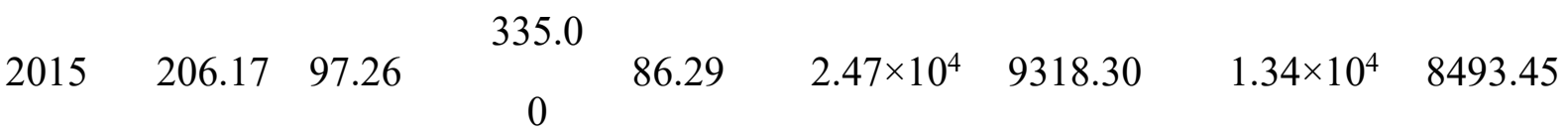

Western

\begin{tabular}{ccccccccc}
2011 & 53.67 & 29.78 & 70.00 & 43.12 & 3456.13 & 2312.59 & 2799.78 & 2111.51 \\
2012 & 54.33 & 28.71 & 77.17 & 48.03 & 4428.05 & 2932.54 & 2945.88 & 1820.72 \\
2013 & 60.25 & 36.58 & 87.17 & 56.64 & 5390.67 & 3563.67 & 3219.70 & 1885.22 \\
2014 & 60.58 & 36.72 & 93.67 & 59.25 & 6051.43 & 3991.58 & 3639.21 & 2302.64 \\
& & & 109.6 & & & & & \\
2015 & 68.08 & 44.06 & 7 & 79.32 & 7174.47 & 4874.43 & 4773.29 & 3466.90 \\
& & & & & & & \\
\hline
\end{tabular}

Table 2 Description of output indicators by regions from 2011 to 2015

\begin{tabular}{|c|c|c|c|c|c|c|}
\hline & \multicolumn{2}{|c|}{$\begin{array}{l}\text { The number of outpatient } \\
\text { and emergency visits }\end{array}$} & \multicolumn{2}{|c|}{ The medical income } & \multicolumn{2}{|c|}{$\begin{array}{l}\text { The actual occupancy of } \\
\text { the total bed days }\end{array}$} \\
\hline & Mean & Std.D & Mean & Std.D & Mean & Std.D \\
\hline \multicolumn{7}{|l|}{ Central } \\
\hline 2011 & $1.86 \times 10^{5}$ & 79043.83 & 5662.01 & 2104.91 & $1.39 \times 10^{5}$ & 65552.28 \\
\hline 2012 & $2.19 \times 10^{5}$ & 86754.23 & 6963.09 & 3024.03 & $1.57 \times 10^{5}$ & 75693.70 \\
\hline 2013 & $2.56 \times 10^{5}$ & 86235.59 & 8854.76 & 4557.09 & $1.73 \times 10^{5}$ & 83757.99 \\
\hline 2014 & $3.05 \times 10^{5}$ & 110032.43 & $1.07 \times 10^{4}$ & 5512.41 & $2.02 \times 10^{5}$ & 123523.01 \\
\hline 2015 & $3.21 \times 10^{5}$ & 122256.68 & $1.19 \times 10^{4}$ & 6453.07 & $1.92 \times 10^{5}$ & 99334.97 \\
\hline
\end{tabular}

Eastern

$\begin{array}{lllllll}2011 & 3.85 \times 10^{5} & 158729.03 & 7378.27 & 3555.25 & 1.52 \times 10^{5} & 49006.46 \\ 2012 & 4.30 \times 10^{5} & 162836.72 & 9009.34 & 3877.38 & 1.71 \times 10^{5} & 49436.28 \\ 2013 & 4.55 \times 10^{5} & 175350.49 & 1.07 \times 10^{4} & 3863.90 & 1.80 \times 10^{5} & 50880.40 \\ 2014 & 4.75 \times 10^{5} & 176653.36 & 1.23 \times 10^{4} & 4432.74 & 1.92 \times 10^{5} & 50398.01 \\ 2015 & 4.76 \times 10^{5} & 191469.03 & 1.42 \times 10^{4} & 5387.57 & 1.96 \times 10^{5} & 45578.42\end{array}$

Western

$\begin{array}{lllllll}2011 & 7.08 \times 10^{4} & 48729.57 & 1225.73 & 899.08 & 5.68 \times 10^{4} & 51795.49 \\ 2012 & 8.11 \times 10^{4} & 54871.55 & 1536.53 & 1156.15 & 6.40 \times 10^{4} & 58506.34\end{array}$




$\begin{array}{lllllll}2013 & 9.00 \times 10^{4} & 62735.50 & 2199.55 & 1639.07 & 7.29 \times 10^{4} & 66810.40 \\ 2014 & 1.01 \times 10^{5} & 69349.35 & 4304.59 & 5769.06 & 7.39 \times 10^{4} & 66824.32 \\ 2015 & 1.06 \times 10^{5} & 73465.15 & 3182.10 & 2692.09 & 7.20 \times 10^{4} & 68885.48\end{array}$

Table 3 Chinese hospital TE, PTE and SE values reaching 1 number distribution, [n (\%)]

\begin{tabular}{|c|c|c|c|c|c|c|c|c|c|}
\hline \multirow{2}{*}{ Years } & \multicolumn{3}{|c|}{ Central $(\mathrm{N}=12)$} & \multicolumn{3}{|c|}{ Eastern $(\mathrm{N}=12)$} & \multicolumn{3}{|c|}{ Western $(\mathrm{N}=12)$} \\
\hline & $\mathrm{TE}$ & PTE & SE & TE & PTE & SE & TE & PTE & $\mathrm{SE}$ \\
\hline 2011 & $\begin{array}{c}8 \\
(66.67)\end{array}$ & $\begin{array}{c}10 \\
(83.33)\end{array}$ & $\begin{array}{c}9 \\
(75 \%)\end{array}$ & $\begin{array}{c}7 \\
(58.33)\end{array}$ & $\begin{array}{c}10 \\
(83.33)\end{array}$ & $\begin{array}{c}7 \\
(58.33)\end{array}$ & $\begin{array}{c}7 \\
(58.33)\end{array}$ & $\begin{array}{c}10 \\
(83.33)\end{array}$ & $\begin{array}{c}7 \\
(58.33)\end{array}$ \\
\hline 2012 & $\begin{array}{c}9 \\
(75 \%)\end{array}$ & $\begin{array}{c}10 \\
(83.33)\end{array}$ & $\begin{array}{c}9 \\
(75 \%)\end{array}$ & $\begin{array}{c}9 \\
(75 \%)\end{array}$ & $\begin{array}{c}11 \\
(91.67)\end{array}$ & $\begin{array}{c}9 \\
(75 \%)\end{array}$ & $\begin{array}{c}9 \\
(75 \%)\end{array}$ & $\begin{array}{c}9 \\
(75 \%)\end{array}$ & $\begin{array}{c}10 \\
(83.33)\end{array}$ \\
\hline 2013 & $\begin{array}{c}9 \\
(75 \%)\end{array}$ & $\begin{array}{c}9 \\
(75 \%)\end{array}$ & $\begin{array}{c}9 \\
(75 \%)\end{array}$ & $\begin{array}{c}10 \\
(83.33)\end{array}$ & $\begin{array}{c}11 \\
(91.67)\end{array}$ & $\begin{array}{c}10 \\
(83.33)\end{array}$ & $\begin{array}{c}9 \\
(75 \%)\end{array}$ & $\begin{array}{c}7 \\
(58.33)\end{array}$ & $\begin{array}{c}7 \\
(58.33)\end{array}$ \\
\hline 2014 & $\begin{array}{c}8 \\
(66.67)\end{array}$ & $\begin{array}{c}9 \\
(75 \%)\end{array}$ & $\begin{array}{c}8 \\
(66.67)\end{array}$ & $\begin{array}{c}8 \\
(66.67)\end{array}$ & $\begin{array}{c}11 \\
(91.67)\end{array}$ & $\begin{array}{c}8 \\
(66.67)\end{array}$ & $\begin{array}{c}9 \\
(75 \%)\end{array}$ & $\begin{array}{c}9 \\
(75 \%)\end{array}$ & $\begin{array}{c}9 \\
(75 \%)\end{array}$ \\
\hline 2015 & $\begin{array}{c}9 \\
(75 \%)\end{array}$ & $\begin{array}{c}10 \\
(83.33)\end{array}$ & $\begin{array}{c}9 \\
(75 \%)\end{array}$ & $\begin{array}{c}8 \\
(66.67)\end{array}$ & $\begin{array}{c}9 \\
(75 \%)\end{array}$ & $\begin{array}{c}8 \\
(66.67)\end{array}$ & $\begin{array}{c}8 \\
(66.67)\end{array}$ & $\begin{array}{c}9 \\
(75 \%)\end{array}$ & $\begin{array}{c}8 \\
(66.67)\end{array}$ \\
\hline
\end{tabular}

Table 4 Regional Malmquist Index for the hospitals, 2011-2015

\begin{tabular}{|c|c|c|c|c|c|c|}
\hline Years & Regions & $\begin{array}{c}\text { TEC }(1)=(3)^{*} \\
(4)\end{array}$ & $\mathrm{TC}(2)$ & PTEC (3) & SEC (4) & $\begin{array}{c}\text { TFPC }(5)=(1)^{*} \\
(2)\end{array}$ \\
\hline \multirow[t]{3}{*}{$2011-2012$} & Central & 0.961 & 1.053 & 0.972 & 0.988 & 1.012 \\
\hline & Eastern & 0.993 & 1.086 & 1.000 & 0.994 & 1.079 \\
\hline & $\begin{array}{c}\text { Wester } \\
\mathrm{n}\end{array}$ & 1.008 & 1.161 & 0.980 & 1.028 & 1.171 \\
\hline \multirow[t]{3}{*}{$2012-2013$} & Central & 1.013 & 1.208 & 1.026 & 0.987 & 1.223 \\
\hline & Eastern & 0.995 & 1.030 & 1.000 & 0.995 & 1.025 \\
\hline & $\begin{array}{c}\text { Wester } \\
\mathrm{n}\end{array}$ & 0.962 & 0.693 & 0.981 & 0.981 & 0.667 \\
\hline 2013-2014 & Central & 0.911 & 0.892 & 0.995 & 0.915 & 0.813 \\
\hline
\end{tabular}




\begin{tabular}{|c|c|c|c|c|c|c|}
\hline & Eastern & 0.990 & 0.997 & 0.995 & 0.995 & 0.987 \\
\hline & $\begin{array}{c}\text { Wester } \\
\mathrm{n}\end{array}$ & 1.064 & 1.072 & 1.040 & 1.023 & 1.140 \\
\hline \multirow[t]{3}{*}{ 2014-2015 } & Central & 1.106 & 0.957 & 1.006 & 1.100 & 1.059 \\
\hline & Eastern & 1.003 & 0.905 & 0.994 & 1.009 & 0.907 \\
\hline & $\begin{array}{c}\text { Wester } \\
n\end{array}$ & 0.985 & 0.854 & 1.000 & 0.985 & 0.841 \\
\hline \multirow{3}{*}{$\begin{array}{c}\text { Geometric } \\
\text { mean }\end{array}$} & Central & 0.995 & 1.021 & 1.000 & 0.995 & 1.016 \\
\hline & Eastern & 0.995 & 1.002 & 0.997 & 0.998 & 0.997 \\
\hline & $\begin{array}{c}\text { Wester } \\
n\end{array}$ & 1.004 & 0.927 & 1.000 & 1.004 & 0.930 \\
\hline
\end{tabular}


Figures

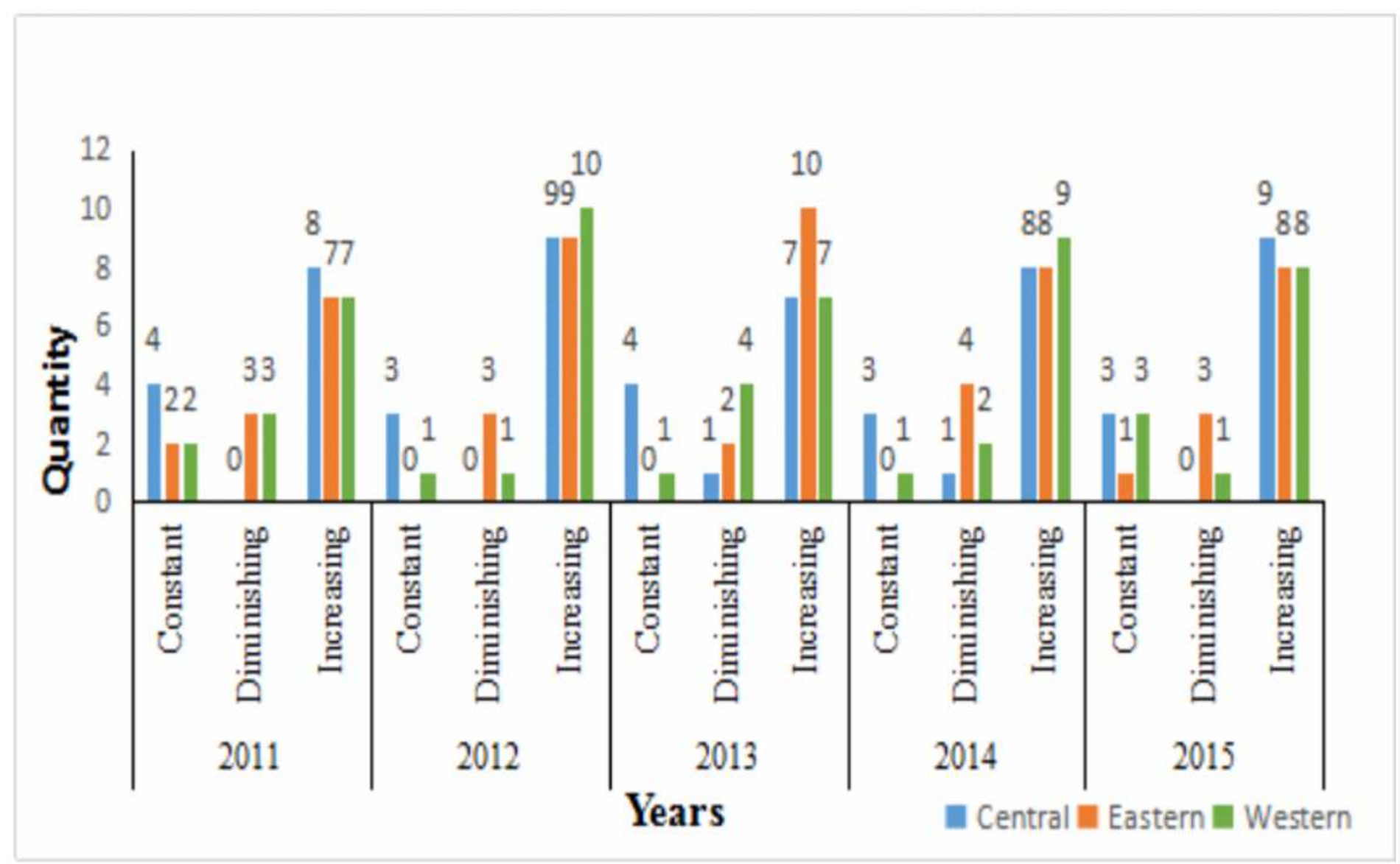

Figure 1

Returns to scale of public hospitals at the county level from 2011-2015 in the various Chinese regions 


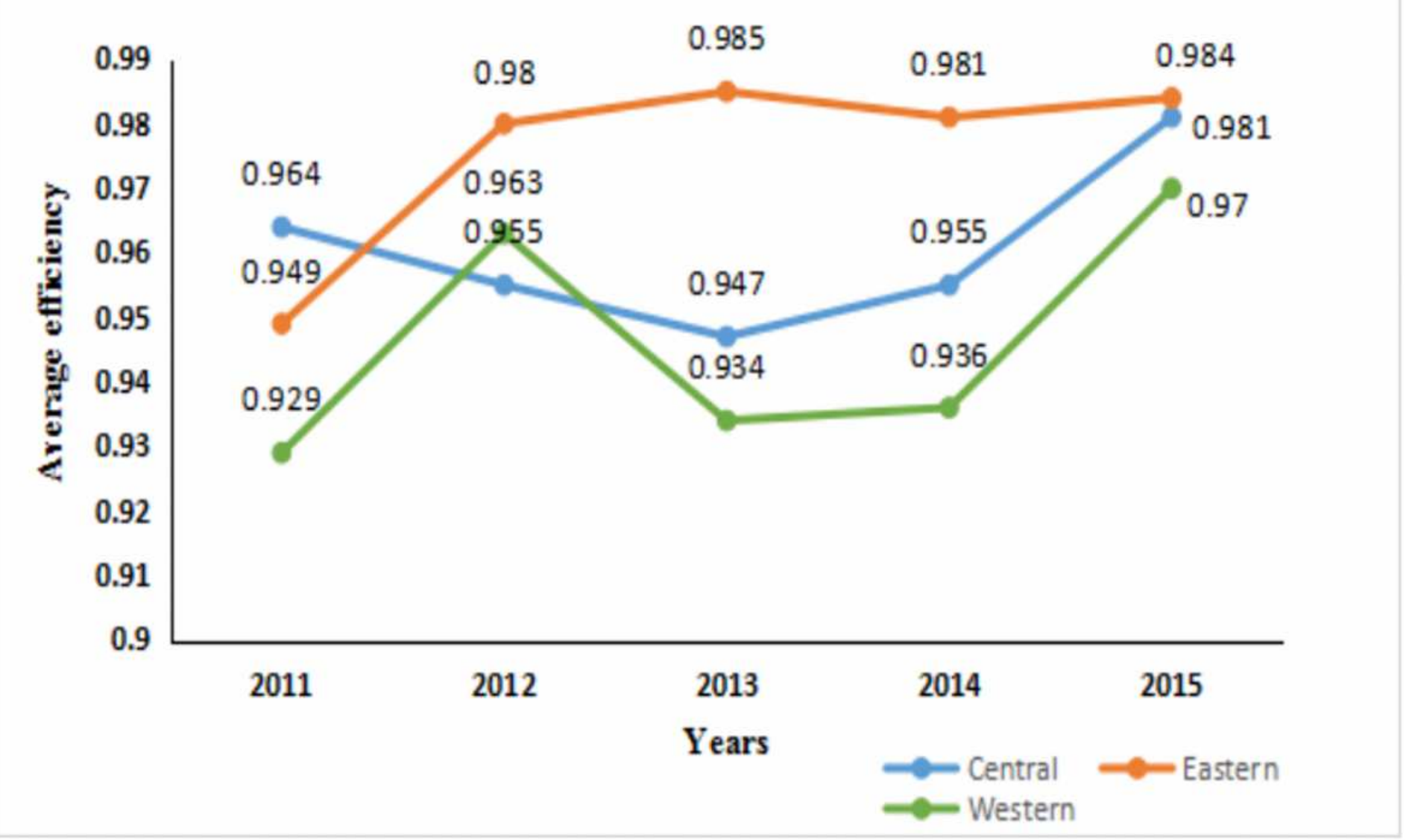

Figure 2

Average TE of public hospitals at the county level in the different regions from 2011-2015 


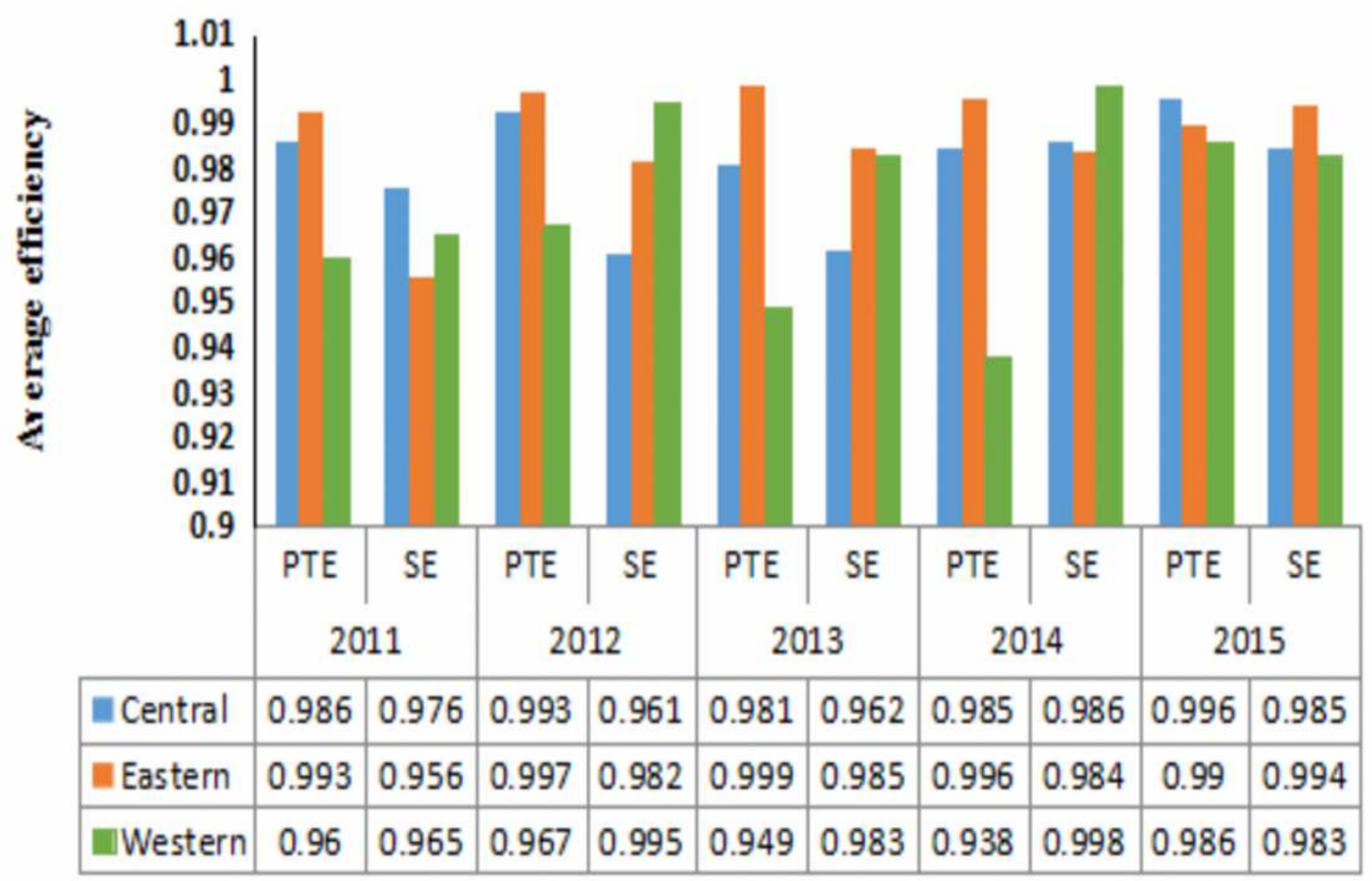

\section{Years}

Figure 3

Average PTE and SE of public hospitals at the county level in the different Chinese regions from 20112015 


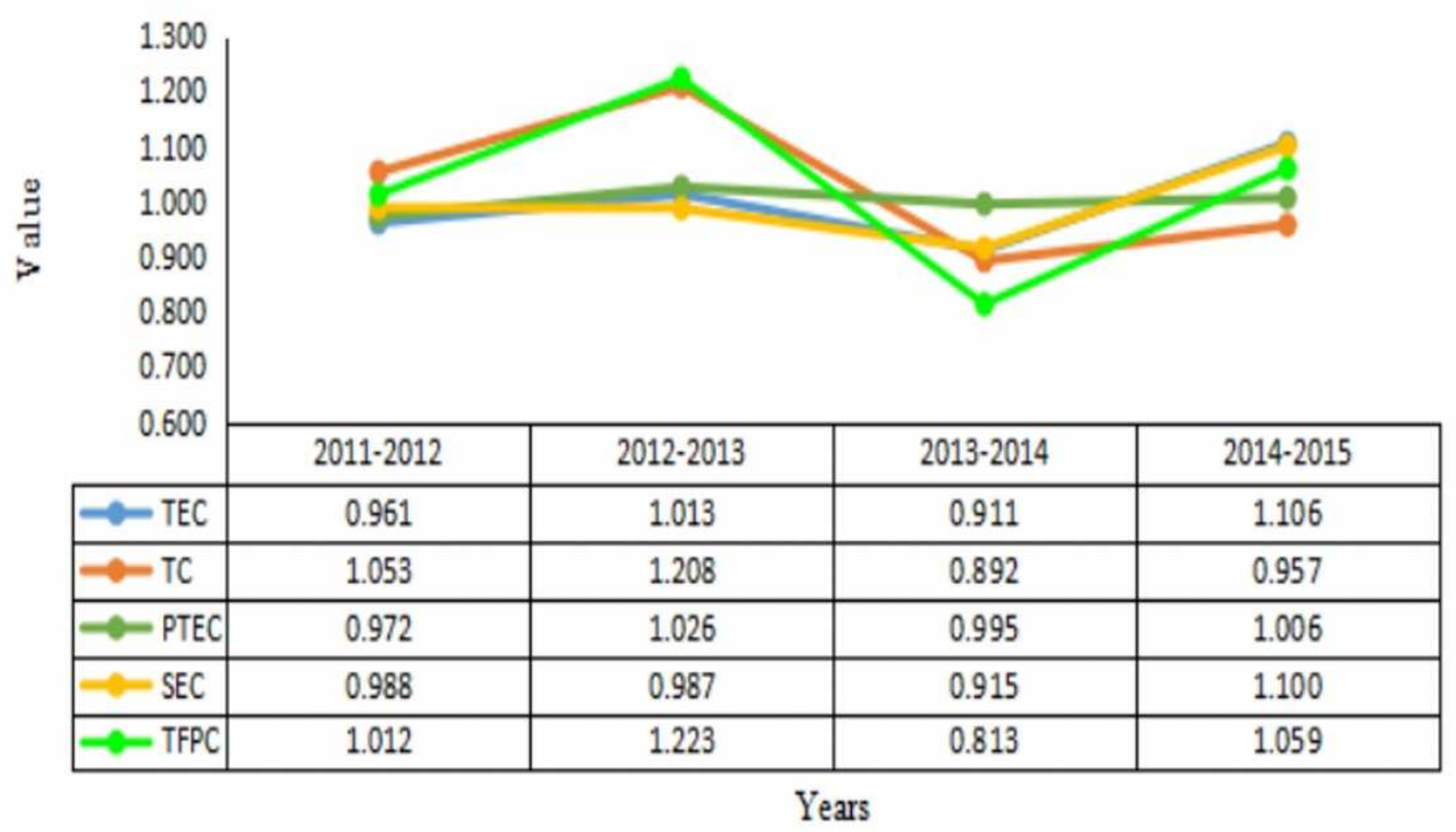

Figure 4

TEC, TC, PTEC, SEC and TFPC in the central Chinese region from 2011-2015 


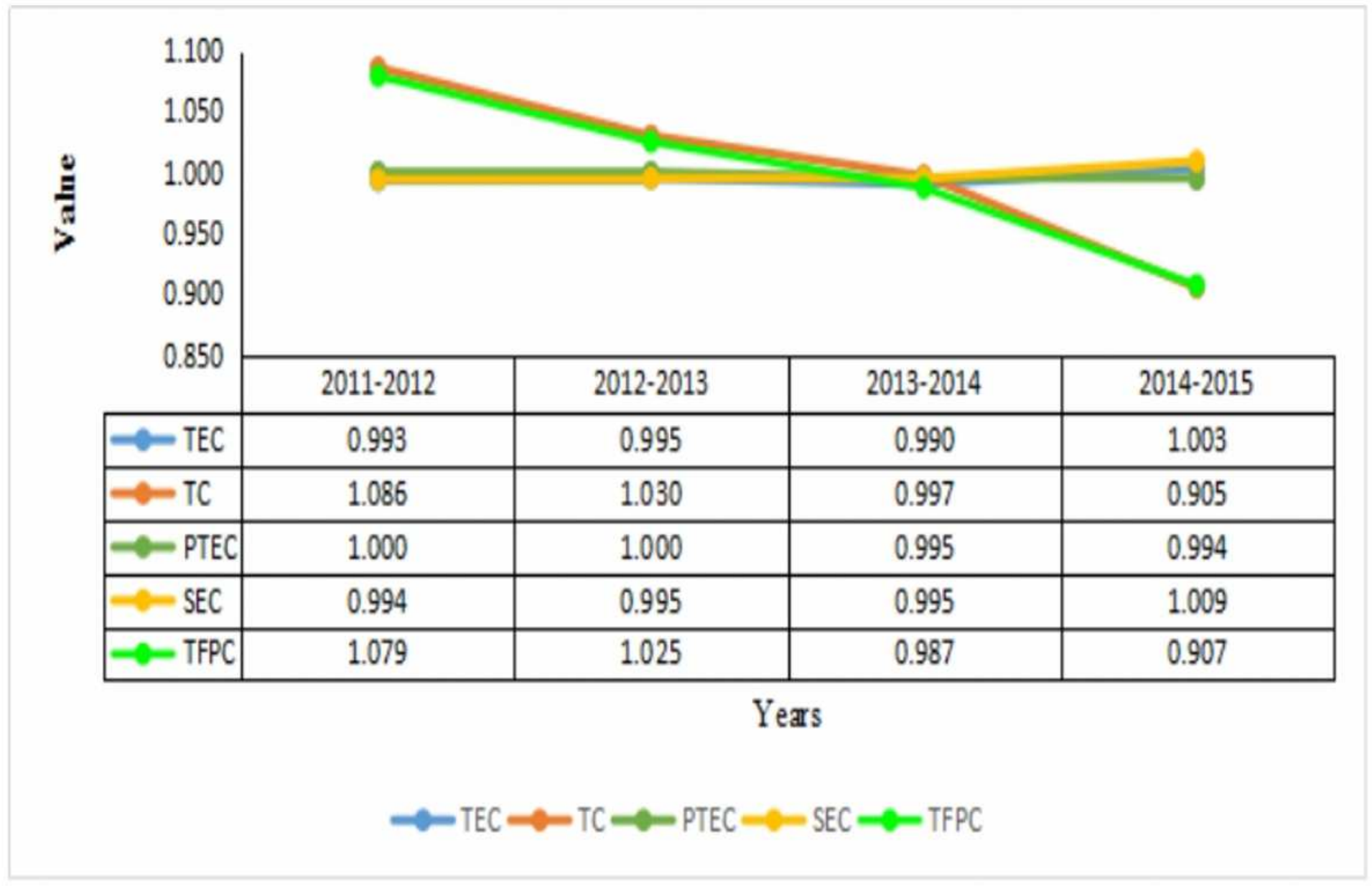

Figure 5

TEC, TC, PTEC, SEC and TFPC in the eastern Chinese region from 2011-2015 


\begin{tabular}{|c|c|c|c|c|}
\hline \\
\hline \multicolumn{5}{|l|}{$\begin{array}{l}0.800 \\
0.600\end{array}$} \\
\hline \multicolumn{5}{|l|}{0.400} \\
\hline \multicolumn{5}{|l|}{0.200} \\
\hline \multirow{2}{*}{0.000} & & & & \\
\hline & $2011-2012$ & $2012-2013$ & $2013-2014$ & $2014-2015$ \\
\hline$\approx$ TEC & 1.008 & 0.962 & 1.064 & 0.985 \\
\hline$\approx \mathrm{TC}$ & 1.161 & 0.693 & 1.072 & 0.854 \\
\hline$\leadsto$ PTEC & 0.980 & 0.981 & 1.040 & 1.000 \\
\hline$-\mathrm{SEC}$ & 1.028 & 0.981 & 1.023 & 0.985 \\
\hline$-\mathrm{TFPC}$ & 1.171 & 0.667 & 1.140 & 0.841 \\
\hline \multicolumn{5}{|c|}{ Years } \\
\hline
\end{tabular}

Figure 6

TEC, TC PTEC, SEC and TFPC in the western Chinese region from 2011-2015 